\title{
Halo size under distance and near conditions in refractive multifocal intraocular lenses
}

Stefan Pieh, Birgit Lackner, Georg Hanselmayer, Richard Zöhrer, Markus Sticker, Herbert Weghaupt, Adolf Fercher, Christian Skorpik

\begin{abstract}
Aims-To calculate the diameter of halos perceived by patients with multifocal intraocular lenses (IOLs) and to stimulate halos in patients with refractive multifocal IOLs in a clinical experiment.

Methods-Calculations were done to show the diameter of halos in the case of the bifocal intraocular lens. 24 patients with a refractive multifocal IOLs and five patients with a monofocal IOL were asked about their subjective observation of halos and were included in a clinical experiment using a computer program (Glare \& Halo, FW Fitzke and C Lohmann, Tomey AG) which simulates a light source of 0.15 square degrees (sq deg) in order to stimulate and measure halos. Halo testing took place monoculary, under mesopic conditions through the distance and the near focus of the multifocal lens and through the focus of the monofocal lens.
\end{abstract}

Results-The halo diameter depends on the pupil diameter, the refractive power of the cornea, and distance focus of the multifocal IOL as well as the additional lens power for the near focus. 23 out of 24 patients with a refractive multifocal IOL described halos at night when looking at a bright light source. Only one patient was disturbed by the appearance of halos. Under test conditions, halos were detected in all patients with a refractive multifocal IOL. The halo area testing through the distance focus was $1.05 \mathrm{sq}$ deg \pm 0.41 , through the near focus $1.07 \mathrm{sq} \mathrm{deg} \pm 0.49$ and in the monofocal lens $0.26 \mathrm{sq}$ deg \pm 0.13 .

Conclusions-Under high contrast conditions halos can be stimulated in all patients with multifocal intraocular lenses. The halo size using the distance or the near focus is identical.

(Brf Ophthalmol 2001;85:816-821)

The word halo is used to denote a dim disc of light or a blurred circle surrounding the images of a light source. Halos are commonly observed when looking through an ice cloud at the moon or the sun. In this case the ice particles lead to scattering. In the case of optical media dimming of the eye-for example, in keratopathy or cataract, halos are often perceived when looking at a light source at night. In this case too, the light is deviated by scattering. The essential point in the formation of halos is that light rays are directed outside the focused image. Sometimes patients with multifocal intraocular lenses (IOLs) also report seeing halos ${ }^{12}$ when looking at a bright light source at night. Because of the clear media of multifocal IOLs the formation of halos must be explained by a different mechanism. Most multifocal lenses include two main focal points. The first one, comparable with the focal point in a monofocal IOL, focuses all distant objects sharply on the retina. The second focal point is generated by the same lens power plus approximately $3.5 \mathrm{D}$, depending on the lens type, to focus objects at reading distance sharply on the retina. The most common types of multifocal lenses are either diffractive or refractive. Diffractive IOLs acquire a second focal point by diffraction of light at concentric circles on the posterior surface of the lens, similar to the physical principle of the Fresnel phase plate. ${ }^{3}$ Today, the most common diffractive multifocal IOL is the $811 \mathrm{E}$ (Pharmacia) made of PMMA (poly(methylmethacrylate)). In our investigations we used a refractive multifocal IOL (SA 40N, Allergan). In this lens five annular aspherical zones are incorporated in the anterior surface of the lens to obtain the multifocal function. Each zone contains continuous curves of refractive power up to $3.5 \mathrm{D}$. The central $2 \mathrm{~mm}$ is used mainly for the distance focus. The light distribution varies with pupil size. At a pupil diameter of $4 \mathrm{~mm}$ $50 \%$ is directed to the distance focus point, $35 \%$ to the near focus point, and $15 \%$ to intermediate foci. A ray diagram shows the theoretical origin of halos (Fig 1). Two different situations were taken into consideration, the first with an object at infinity and the second with an object at reading distance. Halos form because the out of focus image has a larger diameter than the sharp image on the retina.

The aim of our investigation was to calculate the diameter of halos in multifocal lenses. Subjective observations of halos and disturbance caused by them in patients with refractive multifocal lenses were evaluated by means of a questionnaire. Further, halos were stimulated and measured in a clinical experiment.

\section{Methods}

Using the lens formula the halo diameter was calculated in a simplified model.

In clinical testing, 24 eyes of 24 patients (73.6 ( \pm 9.3$)$ years, range 52.3-89.9 years) with a refractive multifocal IOL (SA $40 \mathrm{~N}$, Allergan) made of high refractive silicone and five eyes of five patients $(75.4( \pm 6.0)$ years, range 66.6-82.0 years) with a monofocal IOL of the same material (SI $40 \mathrm{NB}$, Allergan)
Accepted for publication 5 February 2001 

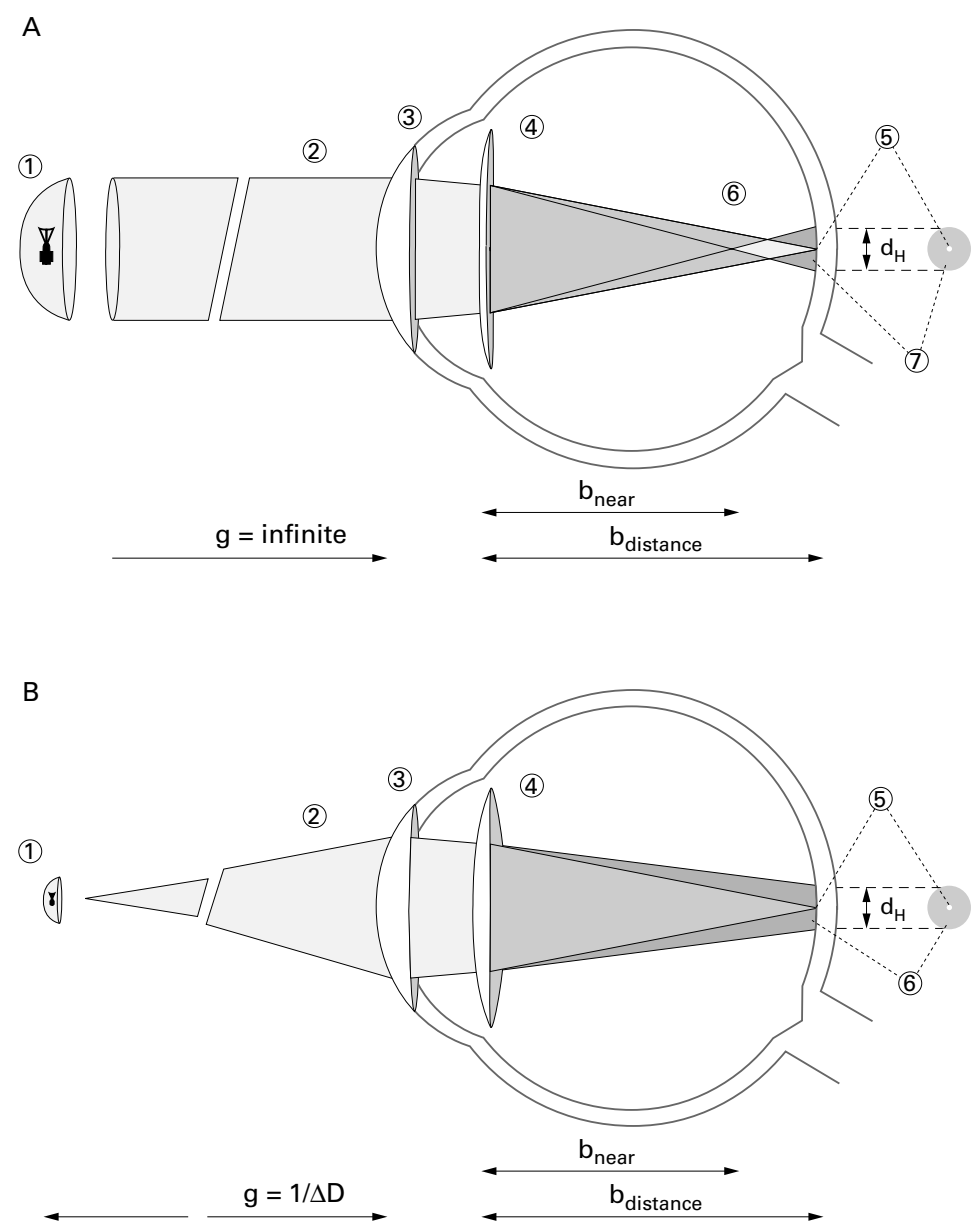

Figure 1 (A) A light source nearly at infinity (1) emits parallel light rays (2) that are bent at the cornea (3) and the bifocal lens (4). The distance focus of the bifocal lens produces a sharp image on the retina (5). In the axial presentation this image is shown as a white spot (5). The near focal point in this constellation is in front of the retina (6) producing an out of focus image on the retina (7). The greater diameter of the out of focus image is represented by the dark grey shading in the axial presentation (7) around the focused image (5). (B) A light source is positioned at the reading distance (1) and the light rays reaching the cornea are drawn in (2). These rays are bent at the cornea (3) and the bifocal lens (4). The near focus of the bifocal lens produces a sharp image on the retina (5) also seen in the axial presentation (5). The far focus of the lens would produce an image behind the retina, producing an out of focus image on the retina (6). The greater diameter of this out of focus image is responsible for the halo (6). $g=$ object distance; $b_{\text {near }}=$ image distance produced by the near focus; $b_{\text {distance }}=$ image distance produced by the distance focus, $d_{H}=$ halo diameter; $\Delta D=$ power difference between the distance and near focus.

were investigated. The following exclusion criteria were applied: (1) pathologies of the cornea, such as corneal dystrophies; (2) clinically relevant opacification of the posterior capsule that could lead to light scattering; (3) pathologies of the vitreous and retina-for example, diabetic retinopathies or age related macula degeneration, which could influence the visual acuity verified with the slit lamp; (4) a pupil diameter at 12 lux of under $3 \mathrm{~mm}$ determined with the Goldmann perimeter; (5) astigmatism over $2 \mathrm{D}$ specified with a manual keratoscope (Zeiss). All lenses were implanted in the bag through a $3.2 \mathrm{~mm}$ clear corneal incision after curvilinear capsulorhexis and phacoemulsification. Postoperatively, examinations were performed after $11.3( \pm 4.8)$ months (range 7.9-22.5 months) in the multifocal group and $12.8( \pm 3.4)$ months (6.1-15.1 month) in the monofocal group. All patients had to fill out a questionnaire regarding their subjective observations of halos, driving habits at night, and distraction by the light of oncoming traffic at night. The results were reported as yes or no answers. For each patient, distance refraction and visual acuity were determined using a standard Snellen projector system (Möller-Wedel M1000) at a viewing distance of 6 metres. The pupil size was measured with a Goldmann perimeter (Haag-Streit) using the integrated millimetre scale and varying the illumination at 12 lux and 170 lux controlled by a commercially available light meter. The computer program Glare \& Halo (FW Fitzke and C Lohmann, Tomey AG) was used to measure the extent of the halo. Against a background luminance of $0.01 \mathrm{~cd} / \mathrm{m}^{2}$, a white light source $15 \mathrm{~mm}$ in diameter with a luminance of $56.6 \mathrm{~cd} / \mathrm{m}^{2}$ appeared in the centre of the video monitor (NEC MultiSync 6FGp, 21 inch flat picture tube, $0.28 \mathrm{~mm}$ distance between points). The appropriate luminance was determined using a calibration program and a luminance meter. The patient sat 2 metres away from the video monitor. Monocular testing took place under mesopic conditions without dark adaptation, with best distance refraction adding plus $0.5 \mathrm{D}$ for the viewing distance. Glasses were always used. The program simulated a movable red spot, which was controlled by the computer mouse and could be directed along 12 lines from the periphery to the centre (Fig 2A). The task for the patient was to state when the spot reached the border of a possible halo. The program computed the area automatically and the result was defined as the area within the indicated halo margins. The results were expressed in square degrees (sq deg) and compared to the area of the light source of $0.15 \mathrm{sq}$ deg. The test was repeated in the same way but with best distance refraction adding minus $2.5 \mathrm{D}$ to force the patient to use the near focus. The results of the halo through the distance focus were corrected by minus $1 \%$ to compensate for the magnification ${ }^{4}$ of the plus $0.5 \mathrm{D}$ glass used in addition to the best distance correction for the viewing distance of 2 metres. Because of the diminution of the minus glasses ${ }^{4}$ of $2.5 \mathrm{D}$, the halos were increased by $5 \%$ when looking through the near focus. Five eyes of five patients with a monofocal IOL (SI $40 \mathrm{NB}$, Allergan) were evaluated in the same way to achieve a reference range for a possible halo size in monofocal lenses. To analyse the significance of the differences between the multifocal and monofocal group and the different halo tests within the multifocal group the MannWhitney test was applied.

\section{Results}

To compare the halo diameters the lens formula

$$
1 / f=1 / g+1 / b
$$

where $\mathrm{f}=$ focus distance; $\mathrm{g}=$ object distance; $\mathrm{b}$ $=$ image distance was used (Fig 1).

Furthermore, it was assumed that the bifocal function was valid over the whole pupil diameter $\left(d_{p}\right)$. The refractive power $(D=1 / f)$ of the eye was defined:

$$
\mathrm{D}_{\text {Cornea }}+\mathrm{D}_{\text {IOLdistance }}=\mathrm{D}_{\text {distance }}=\mathrm{D}
$$


$\mathrm{D}_{\text {Cornea }}+\mathrm{D}_{\text {IOLnear }}=\mathrm{D}_{\text {near }}=\mathrm{D}_{\text {near }}=\mathrm{D}+\Delta \mathrm{D}$

$\mathrm{D}_{\text {Cornea }}=$ doptric power of the cornea

$\mathrm{D}_{\text {IoLdistance }}=$ dioptric power of the distance focus of the multifocal IOL

$\mathrm{D}_{\text {IOLnear }}=$ dioptric power of the near focus of the multifocal IOL

Halo diameter with object at infinity $(\mathrm{g}=\infty)$ :

$$
\begin{aligned}
& b_{\text {near }}=f_{\text {near }}=\frac{1}{D+\Delta D} \\
& b_{\text {distance }}=f_{\text {distance }}=\frac{1}{D} \\
& d_{H}=d_{P} \cdot \frac{b_{\text {distance }}-b_{\text {near }}}{b_{\text {near }}} \\
& \Rightarrow d_{H}=d_{P} \cdot\left(\frac{b_{\text {distance }}}{b_{\text {near }}}-1\right) \\
& \quad=d_{P} \cdot\left(\frac{D+\Delta D}{D}-1\right)=d_{P} \cdot \frac{\Delta D}{D}
\end{aligned}
$$

Halo diameter with object at reading distance $(\mathrm{g}=1 / \Delta \mathrm{D}))$ :

$$
\begin{gathered}
b_{\text {near }}=\frac{1}{1 / f_{\text {near }}-1 / g}=\frac{1}{(D+\Delta D)-\Delta D}=\frac{1}{D} \\
b_{\text {distance }}=\frac{1}{1 / f_{\text {distance }}-1 / g}=\frac{1}{D-\Delta D} \\
d_{H}=d_{P} \cdot \frac{b_{\text {distance }}-b_{\text {near }}}{b_{\text {distance }}} \\
\Rightarrow d_{H}=d_{P} \cdot\left(1-\frac{b_{\text {near }}}{b_{\text {distance }}}\right) \\
=d_{P} \cdot\left(1-\frac{D-\Delta D}{D}\right)=d_{P} \cdot \frac{\Delta D}{D}
\end{gathered}
$$

So the halo diameter is theortically identical when looking at infinity and at reading distance in this model.

Summarising the results of the questionnaire, 23 of 24 patients with a refractive multifocal IOL observed halos by night when looking at a bright light source. Only one patient felt bothered by the halo. Six of the 24 patients had experienced driving at night with a multifocal lens in one eye, and all of them reported halos originating from the oncoming traffic. One of these six patients claimed to be disturbed by halos produced by the oncoming traffic. In the monofocal group none of the five patients observed halos by night. Three of them were drivers but no one reported problems with lights of the oncoming traffic at night. With the best distance refraction $(-1.18$ $\mathrm{sph} \pm 0.78=+0.72 \mathrm{cyl} \pm 0.65)$ the mean distance visual acuity was Snellen $0.91 \pm 0.19$ in the multifocal group. The mean best corrected visual acuity in the monofocal group was, with a mean correction of $+0.38 \mathrm{sph} \pm 0.91=+$ $0.25 \mathrm{cyl} \pm 0.0$, Snellen $0.99 \pm 0.13$. The pupil diameter in the multifocal group was $4.1 \mathrm{~mm} \pm$ 0.7 (range $3.2-6.0 \mathrm{~mm}$ ) at 12 lux and $3.3 \mathrm{~mm}$ \pm 0.7 (range $2.0-5.0 \mathrm{~mm}$ ) at $170 \mathrm{lux}$, and in the monofocal group $4.0 \mathrm{~mm} \pm 0.1$ (range 3.9-4.1 $\mathrm{mm}$ ) at 12 lux and $3.3 \mathrm{~mm} \pm 0.3$ (range $3.0-3.7 \mathrm{~mm}$ ) at 170 lux. The halo size was 1.05 sq deg \pm 0.41 using the distance focus and 1.07 sq deg \pm 0.49 using the near focus (Fig 2B, C).
Halos were found to be irregular in shape in this experimental set-up. In the group with the monofocal IOL the result of the halo test was 0.26 sq deg \pm 0.13 (Fig 2D). Comparison of halo size in both multifocal experiments with that of the monofocal group using the unpaired $t$ test revealed a significant difference ( $\mathrm{p}$ $<0.05$ ); no significant difference in halo size was found between the two multifocal groups.

\section{Discussion}

Halos that form because of unclear optical media of the eye are the result of directing light outside the required focal point. Under physiological conditions, image formation by the cornea and the lens is obstructed by spherical and chromatic aberration. However, several factors which direct the light outside the focused margins can impair the retinal image. The image on the retina is the basis for our visual impression modified by retinal and cortical processing of the data gathered. Thus halos on the retina are not necessarily physiologically recognised. The subjective observation of halos requires specific light conditions and a certain amount of light outside the focused margins. Whereas, in general, halos are physical phenomena of light scattering as in patients with cataract, this is not the case for multifocal lenses. Because there is an additional focus, the focused image on the retina is overlapped by a second, out of focus image of greater diameter produced by the distance or near focus (Fig 1A, B). The greater diameter (Fig 1A, B) of an out of focus image compared with the focused image is responsible for the halo outside the focused margins in bifocal and multifocal lenses. Similar phenomena also occur in multifocal contact lenses. Optical systems with focal points lying behind each other always lead to an overlap of focused and out of focus images and therefore cause halos.

So far, multifocal lenses that provide the patient with a pseudoaccommodation ${ }^{5-7}$ are the only practicable possibility for overcoming the accommodative loss after cataract surgery. Furthermore, bilateral implantation of multifocal IOLs ${ }^{8}$ and asymmetric concepts ${ }^{8-10}$ in bilateral implantation of multifocal lenses provide patients with satisfactory solutions. Myopic astigmatism can lead to a certain increase of depth of focus. ${ }^{11}$ Other solutions, such as silicon installation in the capsular bag, ${ }^{12} 13$ pinhole lenses, and flexible lenses ${ }^{14}$ with the ability to move forward during the constriction of the ciliary muscle have not yet provided satisfactory results. Pseudoaccommodation is a term describing the ability to use two or more focal points of an IOL for sharp imaging on the retina depending on the object distance. Patients with multifocal implants generally show amazingly good clinical results. ${ }^{15-20}$ This is at variance with in vitro testing results of the optical abilities of bifocal and multifocal lenses, especially to modular transfer function testing (MTF) on an optical bench. ${ }^{21-23}$ Perhaps most images on the retina which the retina and brain are called on to analyse, have a certain amount of haze and blur. The halos of multifocal IOLs 
A

B

Looking through the distance focus of a refractive multifocal IOL $n=24$

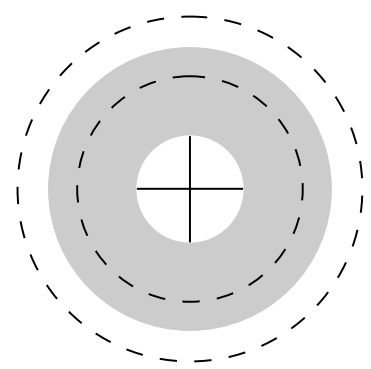

1.05 sq deg \pm 0.41

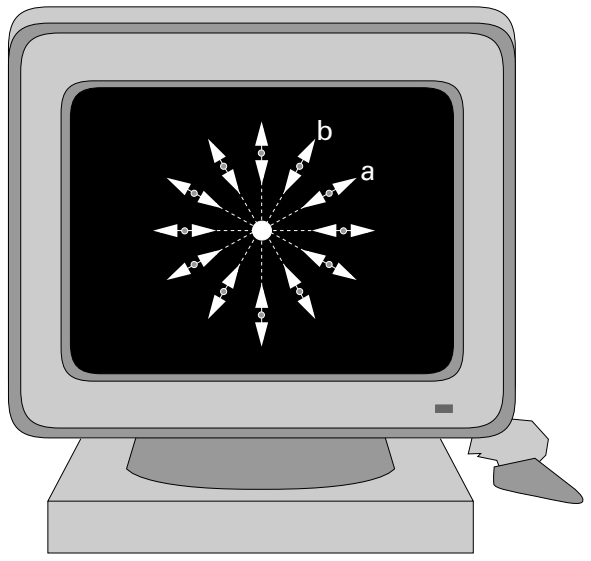

C Looking through the near focus of a refractive multifocal IOL $n=24$

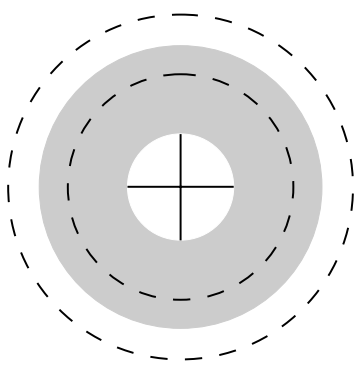

$1.07 \mathrm{sq} \mathrm{deg} \pm 0.49$

NS

$p<0.05$

$p<0.05$

Figure 2 (A) The patient is sitting 2 metres away from a video monitor with the best correction. A white, round light source $15 \mathrm{~mm}$ in diameter with an illumination of $56.6 \mathrm{~cd} / \mathrm{m}^{2}$ is simulated in the centre of the monitor. The background illumination is $0.01 \mathrm{~cd} / \mathrm{m}^{2}$. The test takes place under mesopic conditions. A small red spot can be moved with the computer mouse along lines from the periphery to the centre in $30^{\circ}$ degree steps (a). The task for the patient is to report when the red spot touches the edge of a possible halo. The halo margin is then determined along the next line $30^{\circ}$ away (b). Finally, the extent of the halo is indicated in $30^{\circ}$ steps. The computer program automatically computes the area of the halo. (B-D) The circle in the middle represents the extent of the light source. Monocular testing with best distance refraction plus $0.5 \mathrm{D}$ was performed at a distance of 2 metres under mesopic conditions in order to force the patient to use the distance focus (SA 40 $N)$, and with the best distance refraction plus minus 3.0 D in order to force the patient to use the near focus (SA $40 \mathrm{~N}$ ). In the monofocal group the correction used was the best distance refraction plus $0.5 \mathrm{D}$ (SI $40 \mathrm{NB}$ ). The halo is visible as a grey area; the dotted lines represent the standard deviation. $n s=$ not significant.

add additional confusion, but the basic sharpening mechanisms of the brain are already in place. Clinical evaluations of multifocal lenses revealed that in most clinical standard test methods for measuring the quality of visionfor example, visual acuity determination or even contrast sensitivity measurements, the reduced amount of light that is creating the focus as well as the overlying out of focus image hardly influences the results compared with those for monofocal lenses. In vitro testing ${ }^{21} 22$ showed a loss of contrast in images formed by multifocal lenses. Clinical studies showed that the loss in contrast sensitivity is remarkably small $^{11}{ }^{1620^{24-35}}$ and sometimes even difficult to verify. ${ }^{19}$ Probably the out of focus image does not exert a great influence because the light intensity is reduced by the square of the distance from the focal point and the overlying image is not sharp. In monofocal lenses the patient is also accustomed to light rays that overlie the image because of spherical and chromatic aberrations. In multifocal lenses the amount of light overlying the retinal image is higher, causing greater sensitivity to glare-as has been confirmed in clinical studies. ${ }^{16}{ }^{36-38}$ In several cases discomfort caused through lack of clarity with multifocal lenses has been reported similar to monocular diplopia. ${ }^{39}$ Pseudoaccommodation is the ability to enjoy clear vision at a distance and close up at the same time. In practice, visual acuity decreases rapidly from 
the optical axis to the periphery, so that only fixated objects can be realised with a high resolution. $^{35}$

The lens used is a refractive multifocal lens that distributes the incoming light between the far focus, intermediate foci, and the near focus depending on pupil size. To achieve this light distribution the central $2 \mathrm{~mm}$ section of the lens is mainly used for the distance focus. The advantage of this system is the assurance of good distance vision, especially with a narrow pupil, whereas near visual acuity is worse than in multifocal implants that direct more light to the near focus. ${ }^{15} 19$ Theoretically, the lens also has some intermediate focal points for vision between the reading distance and infinity. In clinical studies, however, these intermediate focal points were found to be insufficient, especially when compared with a diffractive bifocal lens. ${ }^{40}$

The exclusion criteria for patients who underwent the halo test program were determined by avoidance of light scattering phenomena, intact contrast sensitivity, and visual acuity in order to provide independent recognition of halos. Because the central $2 \mathrm{~mm}$ section of the refractive multifocal IOL tested directs the light rays only to the distance focus, pupil size was measured to secure a pupil diameter of $3 \mathrm{~mm}$ at testing conditions. The two illumination levels were chosen because 12 lux was comparable with the light intensity of 10 lux at the cornea plane of the experimental set-up described above and 170 lux simulates normal room illumination. Patients with an astigmatism over $2 \mathrm{D}$ were excluded to minimise a possible influence of halo shape because of light rays outside a focal point caused by the conoid of Sturm. Furthermore, we do not recommend multifocal lenses in the case of postoperative expected astigmatism over $2 \mathrm{D}$ in order not to put at risk the patient's independence of spectacles. ${ }^{18}{ }^{41}$ All computer tests were done with spectacles to achieve comparable results for the halo size.

The lens formula shows that the halo diameter depends on the additional power of the near focus, but also on the power of the cornea and lens and the pupil diameter. Furthermore, it could be shown that theoretically the halo diameter when looking at infinity and at reading distance should be the same (Fig 1 ).

The questionnaire revealed that most patients with refractive multifocal lenses observe halos when looking at a light source at night, but most of them do not feel disturbed by them. In the evaluated patient group, all patients who drive by night described halos originating from the oncoming traffic. One of these six patients felt bothered by the halos when driving by night. The examination of the patients in the monofocal group revealed the expected results. None of the patients had observed halos and no one who was driving by night felt disturbed by the oncoming traffic. The slightly worse best corrected visual acuity in the multifocal group of Snellen 0.91 (SD $0.19)$ compared with the monofocal group of Snellen 0.99 (SD 0.13) seems to be a coincidence and does not correspond with other investigations where the best corrected distance visual acuity in multifocal and monofocal lenses is comparable. ${ }^{342}$ The chosen method of pupil measurement under different light conditions using the Goldmann perimeter was time consuming but showed good, reproducible results. The pupil diameter was comparable in all patients tested. The computer test program proved to give good, reproducible results. The system for visualising the halo along 12 lines proved to be exact and precise enough for our task. The evaluated halo areas of 1.05 sq deg \pm 0.41 looking through the distance focus and $1.07 \mathrm{sq} \mathrm{deg} \pm 0.49$ looking through the near focus revealed that the out of focus image of the near focus that was overlying the image of the distance focus when looking at infinity had a comparable diameter to the out of focus image of the distance focus when looking at reading distance. Comparison of the evaluated size of halos in the multifocal group with that of halos in the monofocal group confirmed the expected statistically significant differences (Fig 2B-D). A difference between halo testing with the computer program used in the clinical experiment and the theoretical considerations was the irregularity of the halo margins. In most cases the evaluated halos in patients with multifocal lenses were of irregular shape. These results also correspond to our clinical experience of halo description given by patients with multifocal lenses. An explanation therefore may be refractive irregularities of the cornea, a possible lens tilt, and difficulties in recognising the weak halo margins exactly.

In order to observe halos in practice a high contrast is necessary between an object and its background-for example, a bright light source by night or, in the clinical experiment described, under mesopic conditions. In summary, halos can be stimulated in all patients with intraocular multifocal lenses but most patients do not feel bothered by them. Theoretically and practically halo size is identical either using the distance or the near focus of a multifocal IOL.

1 Gimbel HV, Sanders DR, Raanan MG. Visual and refractive results of multifocal intraocular lenses. Ophthalmology1991;98:881-7.

2 Rossetti L, Carraro F, Rovati M, et al. Performance of diffractive multifocal intraocular lenses in extracapsular surgery. $\mathcal{F}$ Cataract Refract Surg 1994;20:124-8.

3 Rassow B, Kusel R. Die Optik der diffraktiven Intraokularlinse. In: Schott K, Jacobi KW, Freyler H, eds. 4. Kongre $\beta$ der Deutschen Gesellschaft für Intraokularlinsen Implantatioder Deutschen Gesellschaft für Intraokut Berlin: Springer 1991:339-48.

4 Guyton D, West C, Miller J, et al. Ophthalmic optics and clinical refraction. Wilmer Institute, Baltimore: Johns Hopkins cal refraction

5 Auffahrt GU, Hunold W, Wesendahl TA, et al. Depth of focus and functional results in patients with multifocal intraocular lenses: a long-term follow-up. 7 Cataract Refract Surg 1993;19:685-9.

6 Percival SP, Setty SS. Prospectively randomized trial comparing the pseudoaccommodation of the AMO ARRAY multifocal lens and monofocal lens. $\mathcal{f}$ Cataract Refract Surg 1993;19:26-31.

7 Liekfeld A, Pham DT, Wollensack J. Funktionelle Ergebnisse bei bilateraler Implantation einer faltbaren refraktiven multifokalen Hinterkammerlinse. Klin Monatsbl Augenheilkd 1995;207:283-6.

8 Jacobi FK, Kammann J, Jacobi KW, et al. Bilateral implantation of asymmetrical diffractive multifocal intraocular lenses. Arch Ophthalmol 1999;117:17-23.

9 Jakobi KW, Eisenmann D. Asymmetrische Mehrzonenlinsen-ein neues Konzept mutifokaler Intraokularlinsen. Klin Monatsbl Augenheilkd 1993;202:30914 
10 Eisenmann D, Jacobi KW, Krizok T, et al. Theoretische und klinische Abbildungseigenschaften refraktiver 3-Zonen Multifokallinsen mit unterschiedlicher Gewichtung von Fern-und.

11 Datiles MB, Gancayco T. Low myopia with low astigmatic correction gives cataract surgery patients good depth of focus. Ophthalmology 1990;97:922-6.

12 Hettlich HJ, Hettlich F. Ein mathematisches Modell zur Akkommodation im Hinblick auf injizierbare Intraokularlinsen. In: Pham DT, Wollensack J, Rochels R., Hartmann C, eds. 8. Kongre $\beta$ der Deutschsprachigen Gesellschaft für Intraokularlinsen Implantationen. Berlin: Springer, 1994: 316-20.

13 Reiner J, Speicher L. Eigenschaften durch Injektion erzeugter Intraokularlinsen. Klin Monatsbl Augenheilk 1993;202:49-51.

14 Payer H. Ringwulstlinse mit Zoomwirkung zur Verstärkung einer Pseudoakkommodation und deren Erklärung aus einer Pseudoakkommodation und deren Erklarung aus 1996;10/2:53-5.

15 Weghaupt H, Pieh S, Skorpik C. Comparison of pseudoaccommodation and visual quality between a diffractive and refractive multifocal intraocular lens. $\mathcal{F}$ Cataract Refract Surg 1998;22:663-5.

16 Pieh S, Weghaupt H, Skorpik C. Contrast sensitivity and glare disability with diffractive and refractive multifocal intraocular lenses. F Cataract Refract Surg 1998;22:659-62

17 Arens B, Freudenthaler N, Quentin CD. Binocular function after bilateral implantation of monofocal and refractive multifocal intraocular lenses. F Cataract Refract Surg 1999; 25:399-404.

18 Pieh S, Weghaupt H, Rainer G, et al. Visual acuity and attitude to wearing glasses after implantation of a diffractive multifocal lens. Klin Monatsbl Augenheilkd 1997;210:3842 .

19 Walkow T, Liekfeld A, Anders N, et al. A Prospektive Evaluation of a Diffractive versus a Refractive Designed Multifoation of a Diffractive versus a Refractive Designed Multifo

20 Weghaupt H, Pieh S, Skorpik C. Visual properties of the foldable AMO Array multifocal intraocular lens. 7 Cataract Refract Surg 1996;22(Suppl 2):1313-17.

21 Holladay J, Van Dijk H, Land A, et al. Optical performance of multifocal intraocular lenses. F Cataract Refract Surg 1990;16:413-22.

22 Eisenmann D, Hessemer V, Manzke B, et al. Modulationsübertragungsfunktion und Kontrastempfindlichkeit refraktiver Mehrzonenmultifokallinsen. Ophthalmologe 1993; 90:343-7.

23 Lang A, Portney V. Interpreting multifocal intraocular lens modulation transfers function. I Cataract Refract Surg 1993;19:505-12.

24 Rüther K, Eisenmann D, Zrenner E, et al. Der Einfluß diffraktiver Multifokallinsen auf Kontrastsehen,Gegenlichtsehschärfe und Farbsinn. Klin Monatsbl Augenheilkd 1994; 204:14-19.

25 Olsen T, Corydon L. Contrast sensitivity as a function of focus in patients with the diffractive multifocal intraocular lens. F Cataract Refract Surg 1990;16:703-6.

26 Post CT. Comparison of depth of focus and low-contrast acuities for monofocal versus multifocal intraocular lens patients at 1 year. Ophthalmology 1992;99:1658-64.
27 Ravalico G, Baccara F, Rinalidi G. Contrast sensitivity in multifocal intraocular lenses. $\mathcal{F}$ Cataract Refract Surg 1993; 19:22-5.

28 Williamson W, Poirier L, Coulon P, et al. Compared optical performances of multifocal and monofocal intraocular lenses. Br f Ophthalmol 1994;78:249-51.

29 Eisenmann D, Jacobi KW. Untersuchung der Kontrastempfindlichkeit mit computergestützten Verfahren und Kontrasttafeln: vergleichende Ergebnisse bei mono- und multifokaler Pseudophakie. Akt Augenheilkd 1995;20:2015.

30 Jacobi FK, Eisenmann D. Klinische Ergebnisse der AMO Array Multifokallinse. Spektrum Augenheilkd 1996;10/2:535 .

31 Goes F. Personal results with the $3 \mathrm{M}$ diffractive multifocal intraocular lens. F Cataract Refract Surg 1991;17:577-82.

32 Lindstorm RL. One-year results from 671 patients with the $3 \mathrm{~m}$ multifocal intraocular lens. Ophthalmology 1993;100: 91-7.

33 Liekfeld A, Pham DT, Wollensack J. Funktionelle Ergebnisse einer neuen diffraktiven Bifokallinse versus Monofokallinse. In: Pham DT, Wollensack J, Rochels R, Hartmann C, eds. 8. Kongre $\beta$ der Deutschsprachigen Gesellschaft für Intraokularlinsen Implantationen. Berlin: Springer, 1994:247-53.

34 Vaquero M, Encinas JL, Jimenez F. Visual function with monofocal versus multifocal IOLs. 7 Cataract Refract Surg 1996; 22:1222-5.

35 Roth EH. SinnesphysiologischAspekte des Sehens mit bifokaler Intraokularlinse. In: Neuhann T, Hartmann C, Rochels R, eds. 6. Kongre $\beta$ der Deutschsprachigen Gesellschaft für Intraokularlinsen Implantationen. Berlin: Springer, 1993: $265-9$.

36 Eisenmann D, Jacobi FK, Dick B, et al. Untersuchungen zur Blendempfindlichkeit phaker und pseudophaker Augen. Klin Monatsbl Augenheilkd 1996;208:87-92.

37 Winther-Nielson A, Corydon L, Olsen T. Contrast sensitivity and glare in patients with a diffractive multifocal intracular lens. F Cataract Refract Surg 1993;19:254-7.

38 Hessemer V, Frohloff H, Eisenmann D, et al. Mesopisches Sehen bei multi- und monofokaler Pseudophakie und phaken Kontrollaugen. Ophthalmologe 1994;91:465-8.

39 Ellingson FT. Explantation of $3 \mathrm{M}$ diffractive intraocular lenses. F Cataract Refract Surg 1990;16:697-702.

40 Pieh S, Lackner B, Zöhrer R, et al. Pseudoakkommodation und Kontrastsehschärfe diffraktiver und refraktiver Multifokallinsen. In: Duncker G, Ohtloff C, Wilhelm F, eds. 12 Kongre $\beta$ der Deutschsprachigen Gesellschaft für Intraokularlinsen Implantationen. Berlin: Springer, 1999:204-7.

41 Eisenmann D, Wagner R, Dick B, Jacobi KW. Einfluß des Hornhautastigmatismus auf die Kontrastempfindlichkeit bei mono- und multifokaler Pseudophakie eine theoretische Studie am physikalischen Auge. Klin Monatsbl Augenheilkd 1996;209:125-31.

42 Eisenmann D, Jacobi KW. Die ARRAY-MultifokallinseFunktionsprinzip und klinische Ergebnisse. Klin Monatsbl Augenheilkd 1993;203:189-94. 